\title{
Pulmonary Safety and Tolerability of Inhaled Levodopa (CVT-301) Administered to Patients with Parkinson's Disease
}

\author{
Peter A. LeWitt, MD, MMSc, Rajesh Pahwa, MD, ${ }^{1}$ Alexander Sedkov, MS, \\ Ann Corbin, $\mathrm{DHSc}^{3}$, Richard Batycky, $\mathrm{PhD}^{3}$, and Harald Murck, $\mathrm{MD}^{3, \dagger}$
}

\begin{abstract}
Background: CVT-301, an inhaled levodopa (LD) formulation, is under development for relief of OFF periods in Parkinson's disease (PD). Previously, we reported that CVT-301 improved OFF symptoms relative to placebo. In this study, we evaluate pulmonary function in patients treated with a single dose of CVT-301 or placebo for 3 hours, or received multiple doses/day for 4 weeks.

Methods: As part of two phase 2 studies, pulmonary safety and tolerability of CVT-301 were evaluated in PD patients experiencing motor fluctuations ( $\geq 2$ hours OFF/day), Hoehn and Yahr stage 1-3, and forced expiratory volume in $1 \mathrm{~second} /$ forced vital capacity ratio $\geq 75 \%$ of predicted (in ON state). In study A, patients received single doses of oral carbidopa/LD and each of the following via the inhaled route: placebo and 25 and $50 \mathrm{mg} \mathrm{LD}$ fine particle dose (FPD) CVT-301. In study B, patients received up to 3 inhaled doses/day of $35 \mathrm{mg}$ (weeks 1-2) and $50 \mathrm{mg}$ LD FPD CVT-301 (weeks 3-4) versus placebo. Assessments included spirometry and treatmentemergent adverse events (TEAEs).

Results: In study A, $(n=24)$ mean age \pm standard deviation was $61.3 \pm 7.4$ years, mean time since diagnosis was $10.5 \pm 4.6$ years, and mean duration of LD treatment $8.4 \pm 3.7$ years. Assessment of pulmonary function (predose to 3 hours postdose) showed that spirometry findings were within normal ranges, regardless of treatment groups, or motor status at screening. In study $\mathrm{B},(n=86)$ mean age was $62.4 \pm 8.7$ years, time since PD diagnosis was $9.4 \pm 3.9$ years, and duration of LD treatment 7.8 \pm 3.9 years. Longitudinal assessment of pulmonary function over 4 weeks showed no significant difference in spirometry between CVT-301 versus placebo groups. In both studies, the most common CVT-301 TEAE was mild-to-moderate cough (study A: $21 \%$; study B: $7 \%$ vs. $2 \%$ in placebo). Other common TEAEs in study B were dizziness and nausea.
\end{abstract}

Conclusion: Acute and longitudinal assessment of pulmonary function showed that CVT-301 treatment was not associated with acute airflow obstruction in this population. CVT-301 was generally safe and well tolerated.

Keywords: antiparkinsonian agents, dyskinesias, idiopathic, inhalation, levodopa, motor disorders, Parkinson's disease, safety, spirometry

\section{Introduction}

$\mathbf{O}$ RAL LEVODOPA (LD) continues to be the pharmacotherapeutic standard for managing Parkinson's disease (PD) motor symptoms. ${ }^{(1)}$ Although LD is very effective in alleviating the symptoms of PD, the oral route of administration can affect drug absorption. ${ }^{(2-5)}$ The variability in drug absorption from the gastrointestinal tract coupled with its short half-life and the continued loss of dopaminergic neurons can affect the plasma concentrations of $\mathrm{LD}$, resulting in motor

\footnotetext{
${ }^{1}$ Department of Neurology, Henry Ford Hospital-West Bloomfield, West Bloomfield, Michigan.

${ }^{2}$ Department of Neurology, University of Kansas Medical Center, Kansas City, Kansas.

${ }^{3}$ Acorda Therapeutics, Inc., Ardsley, New York.

${ }^{\dagger}$ Current affiliation: Clinic of Psychiatry and Psychotherapy, Philipps-University of Marburg, Marburg, Germany.
}

(C) Peter A. LeWitt, et al. 2017; Published by Mary Ann Liebert, Inc. This Open Access article is distributed under the terms of the Creative Commons Attribution Noncommercial License (http://creativecommons.org/licenses/by-nc/4.0/) which permits any noncommercial use, distribution, and reproduction in any medium, provided the original author(s) and the source are credited. 
fluctuations over time, including OFF periods. ${ }^{(6-8)}$ Therefore, an alternative route of delivery that allows a more predictable absorption of LD with less variability is desired. Pulmonary delivery offers an alternative to oral administration of $\mathrm{LD}$, as the drug will reach the epithelium that lines the alveoli capillary network almost immediately, ensuring fast absorption. The large surface area of pulmonary epithelium and the relatively low metabolic activity in the lungs are additional attributes in favor of pulmonary delivery. ${ }^{(9-11)}$

CVT-301 is an investigational inhaled LD formulation that is being developed as a self-administered treatment for OFF periods in patients with PD who experience motor fluctuations with their existing LD regimen. CVT-301 bypasses the challenges associated with an oral route of administration of LD such as the variability of gastric emptying and of gastrointestinal transport and absorption. Through pulmonary inhalation, CVT-301 may provide a rapid and more direct route to the brain for relatively small, supplemental, doses of LD that can extend the coverage produced by the oral medication. In two studies, CVT-301 improved Unified Parkinson's Disease Rating Scale (UPDRS) Part III (motor examination) scores obtained 10-60 minutes after dosing during an OFF period. ${ }^{(12,13)}$

A particular concern with an inhaled formulation is pulmonary safety. Morbidity and mortality, and central or upper airway dysfunction has been described in PD patients, ${ }^{(14,15)}$ and PD may also interfere with a patient's ability to perform pulmonary function tests. ${ }^{(16)}$ This report evaluates the safety profile of CVT-301 from two phase 2 studies of patients with motor fluctuations in PD.

\section{Materials and Methods}

The safety and tolerability of CVT-301 were evaluated in two randomized, double-blind, placebo-controlled studies: a phase 2a study (NCT01617135 [study A] $)^{(12,13)}$ and a phase 2b study (NCT01777555 [study B]). ${ }^{(13)}$

\section{Patients}

Patient selection criteria for study A included: diagnosis of PD; age 30-80 years (inclusive); Hoehn and Yahr stage 1-3 in the ON state and experiencing $\geq 2$ hours of OFF time per waking day; showing acceptable LD responsiveness; with a forced expiratory volume in 1 second $\left(\mathrm{FEV}_{1}\right)>70 \%$ of that predicted for race, age, sex, and height; and with an $\mathrm{FEV}_{1} / \mathrm{FVC}$ (forced vital capacity) ratio $\geq 75 \%$ of predicted in the ON state.

For study B, the selection criteria were similar to those for the patients in study A, with the addition of requiring a sum of UPDRS Part III score difference of $\geq 25 \%$ between ON and OFF states in response to the patient's usual LD dose. The $\mathrm{FEV}_{1}$ had to be $>60 \%$ of predicted, although the $\mathrm{FEV}_{1} / \mathrm{FVC}$ ratio requirement remained $\geq 75 \%$ of predicted in the $\mathrm{ON}$ state.

Both studies required patients to be on a stable oral LD regimen of at least 4 times daily dosing for at least 2 weeks before screening. Other oral treatments included stable dosages of monoamine oxidase type $\mathrm{B}$ and catechol- $O$-methyltransferase inhibitors. Although use of dopamine agonists was permitted, apomorphine was not allowed for 2 weeks (study A) or 4 weeks (study B) before screening and during the studies. Exclusion criteria included chronic respiratory disease within the last 5 years, and clinically significant cognitive impairment (MiniMental State Examination score $<25$ ) for study B.

\section{Design}

Study A. This was a randomized, placebo- and activecontrolled, and double-blind study in patients with PD experiencing OFF periods (Fig. 1A). ${ }^{(17)}$ The active control was a single in-clinic, open-label dose of standard oral carbidopa/LD (25/100 mg). Single in-clinic, double-blind doses of each of three inhaled treatments were then administered in randomized order on separate treatment visits: placebo, CVT-301 $25 \mathrm{mg}$ LD fine particle dose (FPD), and CVT-301 $50 \mathrm{mg}$ LD FPD. Treatment visits were separated by at least 2 days and the duration of study ranged from $\sim 6$ to 12 weeks. Each treatment was administered during an OFF period at least 4 hours after each patient's usual morning dose of oral carbidopa/LD (and breakfast at home) (Fig. 1A). Spirometry was performed for all patients at screening (in both $\mathrm{ON}$ and OFF states) and at each treatment visit, before dosing, and at 60 and 180 minutes postdose.

Study B. This was a randomized, double-blind, placebocontrolled study for the treatment of up to three OFF periods per day in patients with PD. ${ }^{(18)}$ After screening, the patients were randomized in a 1:1 scheme to 4 weeks of at-home, double-blind use of inhaled CVT-301 or placebo up to three times per day, as needed for OFF periods. Subjects were instructed to administer inhaled medication as needed (up to a maximum of three OFF periods) when their OFF symptoms reemerged, before their next scheduled dose of oral LD. For weeks 1 and 2, the treatment was inhaled placebo or CVT-301 $35 \mathrm{mg}$ LD FPD (dose level 1). After 2 weeks, the CVT-301 dose was escalated to $50 \mathrm{mg}$ LD FPD (dose level 2) (Fig. 1B).

Spirometry was performed during screening in both $\mathrm{ON}$ and OFF states and subsequently during an ON state at each study visit (before dosing) and at the follow-up safety visit.

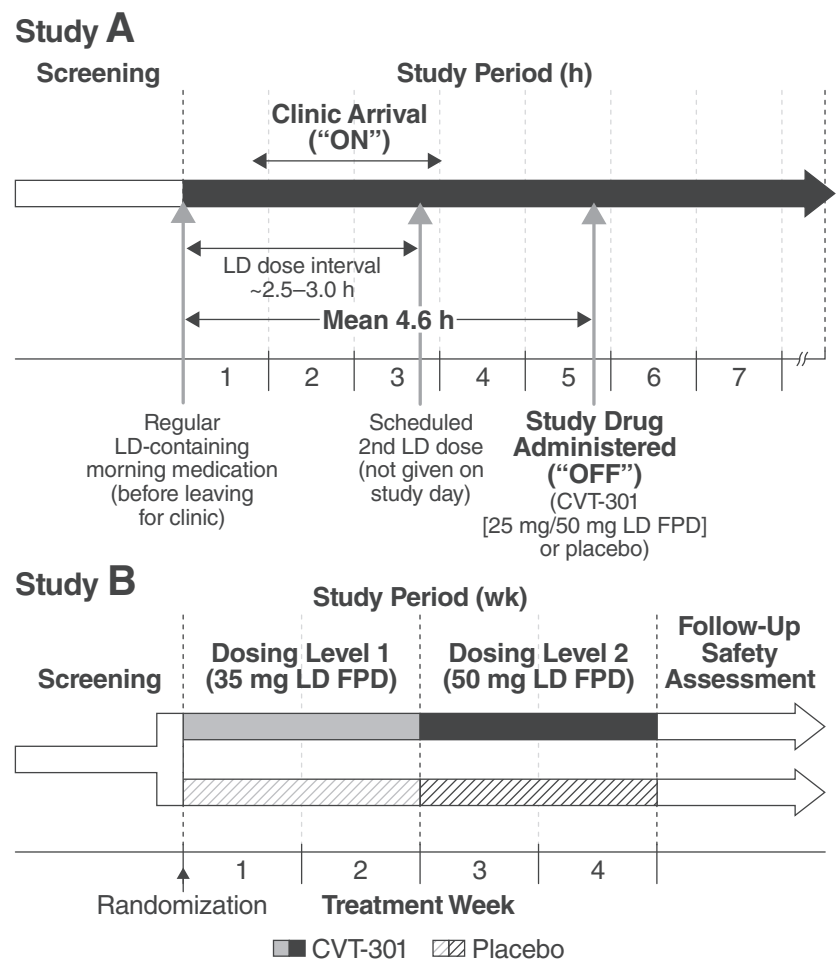

FIG. 1. Study designs. FPD, fine particle dose; LD, levodopa. 
In addition, spirometry determinations were performed immediately predose and postdose at 15,30 , and 60 minutes following the first in-clinic administration of CVT-301 $35 \mathrm{mg}$ LD FPD or placebo and predose and 60 minutes postdose after the administration of $50 \mathrm{mg}$ LD FPD or placebo.

CVT-301. CVT-301 was delivered to the lung using a 5inch long, single-capsule-based, breath-actuated inhaler that uses the ARCUS ${ }^{\circledR}$ pulmonary delivery system. ${ }^{(19)}$ CVT-301 is composed of $90 \% \mathrm{LD}, 8 \%$ dipalmitoyl phosphatidylcholine (DPPC), and $2 \%$ sodium chloride $(\mathrm{NaCl})$. In study A, CVT301 was supplied in size 00 hypromellose (hydroxypropyl methylcellulose or HPMC) capsules, each with a nominal fill weight of $28 \mathrm{mg}$ designed to deliver an estimated $12.5 \mathrm{mg} \mathrm{LD}$ FPD to the lung. To provide the $25 \mathrm{mg}$ LD FPD used in study A, two capsules were required per administration. In study B, CVT-301 was supplied in size 00 HPMC capsules, each at a nominal fill weight of $32 \mathrm{mg}$ CVT-301 (27.6 mg LD per capsule) designed to deliver an approximate FPD of $17.5 \mathrm{mg}$ LD to the lung per capsule inhalation. For dose level 1, two CVT-301 capsules (delivering $\sim 35 \mathrm{mg}$ LD FPD) were inhaled at each administration, and for dose level 2, three CVT301 capsules (delivering $\sim 50 \mathrm{mg}$ LD FPD) were inhaled.

For administration, the capsule was placed into the inhaler and punctured during a simple actuation process, after which the patient inhaled the contents of the encapsulated CVT-301 through the mouthpiece. CVT-301 and placebo capsules were identical in appearance. The placebo consisted of $80 \%$ DPPC and $20 \% \mathrm{NaCl}$ in study A and $100 \%$ lactose in study B. The inhaled placebo was intended to mask any sensation associated with dry powder inhalation to reduce potential patientand rater-based biases on motor function-related endpoints. The placebo was supplied in size 00 HPMC capsules, each with a nominal fill weight of $10 \mathrm{mg}$.

With each inhalation, patients were instructed to take a single deep, comfortable breath followed by a breath hold of $\sim 5$ seconds after administration of each capsule. For the purposes of timing study assessments, time 0 was defined as the time of the start of the final breath hold (second 1 of the $\sim 5$-second breath hold) with the last capsule of inhaled study treatment administered during a dosing visit. In most cases, a single inhalation inhaled the whole contents of the capsule, however, if the capsule needed to be reinhaled, time 0 was at the end of the reinhalation administration.

The inhaler device is designed to be able to be used in low dexterity situations such as experienced by a PD patient during an OFF period.

\section{Safety measures}

Safety was assessed by adverse events (AEs), treatmentemergent AEs (TEAEs), changes in vital signs, clinical chemistry parameters, spirometry, and electrocardiography.

Spirometry was performed under guidelines specified by the Third National Health and Nutrition Examination Survey, ${ }^{(18)}$ the American Thoracic Society (ATS), and the European Respiratory Society (ERS). ${ }^{(20)}$ Spirometry values $\left(\mathrm{FEV}_{1}, \mathrm{FVC}\right.$, and the $\mathrm{FEV}_{1} / \mathrm{FVC}$ ratio) were obtained from each patient's best effort, predefined as the acceptable effort yielding the highest sum of $\mathrm{FEV}_{1}$ and FVC. All spirometry data were reviewed according to ATS/ERS quality standards. The ATS/ERS criteria require that at least 3 of the patient's efforts be acceptable, including an exhalation lasting at least 6 seconds, and that two be repeatable, as shown by a difference of $<0.15 \mathrm{~L}$ between the two $\mathrm{FEV}_{1}$ values and between the two FVC values. Spirometry was performed by trained and qualified personnel using standardized equipment $(6800$ Fleisch Pneumotach; Vitalograph, Inc., Lenexa, KS). ${ }^{(13)}$

\section{Statistical analysis}

Safety measures were assessed descriptively for TEAE incidence and spirometry results. The statistical significance between CVT-301 and placebo groups was assessed using a mixed model for repeated measurements.

\section{Ethics}

Both studies were conducted in accordance with the principles originating in the Declaration of Helsinki, Good Clinical Practices, and local regulatory requirements. The study protocols and informed consent forms were approved by independent ethics committees and institutional review boards, and all patients provided written informed consent.

\section{Results}

\section{Patient characteristics}

The baseline characteristics of the patients in the two studies are summarized in Table 1. In study A, 27 patients were screened and 24 were randomized and treated. One patient did not fulfill 2 of the study dosing visits and was dropped from the completer population; 23 patients completed the study. ${ }^{(17)}$

In study B, 134 patients were screened, 89 were randomized, 86 dosed, and 75 completed the study. At baseline, 24 patients from the placebo (56\%) and 26 patients from CVT-301 group (61\%) had dyskinesia. Six randomized and dosed patients withdrew consent, one was lost to follow-up, and four withdrew, one from the CVT-301 treatment group and three from the placebo group, due to AEs of painful respiration, bradykinesia, chest pain, and wrist fracture. ${ }^{(13)}$

\section{Pulmonary function}

In study $\mathrm{A}$, spirometry parameters showed that predose $\mathrm{FEV}_{1}, \mathrm{FVC}$, and $\mathrm{FEV}_{1} / \mathrm{FVC}$ ratios were generally similar when comparing ON and OFF states (Table 2). Evaluation of mean changes from predose to postdose in $\mathrm{FEV}_{1}, \mathrm{FVC}$, and $\mathrm{FEV}_{1} / \mathrm{FVC}$ ratio showed that the number of patients with $>10 \%$ reduction in $\mathrm{FEV}_{1}$ or FVC following CVT-301 treatments $(n=9)$ was similar to the number reported following active oral carbidopa/LD $(n=6)$ or placebo $(n=8)$ treatments. Figure 2 shows the percent changes in $\mathrm{FEV}_{1}$ and $\mathrm{FEV}_{1} / \mathrm{FVC}$ from predose to 60 and 180 minutes postdose. Maximum percent reductions in $\mathrm{FEV}_{1}$ at 60 minutes postdose for oral carbidopa/LD, placebo, and CVT-301 treatments were $-22,-32$, and -9 , respectively; at 180 minutes the $\mathrm{FEV}_{1}$ reductions were $-30,-14$, and -22 , respectively.

In study B, 77\% (854 out of 1109) of spirometry measurements met ATS criteria, regardless of whether patients were in the ON or OFF state. The most common reason for failure to meet ATS quality criteria was the inability to 
Table 1. Patient Baseline Characteristics

\begin{tabular}{|c|c|c|c|}
\hline \multirow[b]{2}{*}{ Characteristic } & \multirow{2}{*}{$\begin{array}{c}\text { Study } A \\
\text { All treated patients }(\mathrm{n}=24)\end{array}$} & \multicolumn{2}{|c|}{ Study B } \\
\hline & & CVT-301 group $(\mathrm{n}=43)$ & Placebo group $(\mathrm{n}=43)$ \\
\hline \multicolumn{4}{|l|}{ Age, years } \\
\hline Mean (SD) & $61.3(7.4)$ & $62.0(8.4)$ & $62.7(9.1)$ \\
\hline Median [range] & $61[41-75]$ & $62[37-77]$ & $63[43-79]$ \\
\hline \multicolumn{4}{|l|}{ Sex, $n(\%)$} \\
\hline Male & $19(79.2)$ & $25(58.1)$ & $32(74.4)$ \\
\hline Female & $5(20.8)$ & $18(41.9)$ & $11(25.6)$ \\
\hline \multicolumn{4}{|l|}{ Race, $n(\%)$} \\
\hline White & $24(100.0)$ & $41(95.3)$ & 42 (97.7) \\
\hline Other & 0 & $2(4.7)$ & $1(2.3)$ \\
\hline \multicolumn{4}{|c|}{ Time since PD diagnosis, months } \\
\hline Mean (SD) & $126.1(55.5)$ & $108.2(46.0)$ & $117.2(48.1)$ \\
\hline Median [range] & $121.5[29-245]$ & 99 [38-254] & $111[41-255]$ \\
\hline \multicolumn{4}{|c|}{ Duration of LD treatment, months } \\
\hline Mean (SD) & $100.6(43.8)$ & $91.5(45.6)$ & $95.1(47.7)^{\mathrm{a}}$ \\
\hline Median [range] & $91.5[9-175]$ & $85[24-254]$ & $87[15-243]^{\mathrm{a}}$ \\
\hline \multicolumn{4}{|c|}{ OFF time, hours/day, by self-report } \\
\hline Mean (SD) & $4.2(1.8)$ & $3.6(1.5)$ & $3.5(1.6)^{\mathrm{a}}$ \\
\hline Median [range] & $4.0[2-8]$ & $3[2-10]$ & $3[2-10]^{\mathrm{a}}$ \\
\hline \multicolumn{4}{|c|}{ OFF time, hours/day, PD diary data ${ }^{\mathrm{b}}$} \\
\hline Mean (SD) & NA & $5.7(2.2)$ & $5.8(1.8)$ \\
\hline Median [range] & & $5.5[2.2-11.4]$ & $5.8[1.9-9.4]$ \\
\hline \multicolumn{4}{|c|}{ LD total daily dosage, $\mathrm{mg}$} \\
\hline Mean (SD) & $703.6(435.7)$ & $687(276)$ & $853(315)$ \\
\hline Median [range] & $575[200-2100]$ & $688[250-1800]$ & $850[400-1700]$ \\
\hline \multicolumn{4}{|l|}{ LD doses/day } \\
\hline Mean (SD) & $6.0(2.6)$ & $5.6(1.4)$ & $6.1(2.2)$ \\
\hline Median [range] & $5[4-14]$ & $5[4-9]$ & $6[4-15]$ \\
\hline
\end{tabular}

${ }^{\mathrm{a}} n=42$.

${ }^{\mathrm{b}}$ Three-day average, including early-morning OFF time.

LD, levodopa; NA, not available; PD, Parkinson's disease; SD, standard deviation.

perform a repeatable effort, and there were no differences in the reasons for failure between $\mathrm{ON}$ and OFF states.

$\mathrm{FEV}_{1}, \mathrm{FVC}$, and $\mathrm{FEV}_{1} / \mathrm{FVC}$ ratios were within normal ranges and did not differ significantly between the $\mathrm{ON}$ and OFF states at screening (and no CVT-301 treatment). The mean change from predicted $\mathrm{FEV}_{1}(95 \%$ confidence interval) ON-OFF state difference was $-1.4 \%(-3.7,0.9)$. For FVC, the difference was $-0.3 \%(-2.0,1.5)$, and for the $\mathrm{FEV}_{1} / \mathrm{FVC}$ ratio, the difference was $-1.1 \%(-2.0$, $-0.1)^{(21)}$

There was no evidence of adverse effects on lung function when comparing spirometry parameters $\left(\mathrm{FEV}_{1}, \mathrm{FVC}\right.$, and $\left.\mathrm{FEV}_{1} / \mathrm{FVC}\right)$ at predose versus postdose with CVT-301 treatment. Nor were there any significant differences in these parameters between CVT-301 and placebo over 4 weeks of double-blind treatment, as shown in Table 3; maximum reductions in $\mathrm{FEV}_{1}$ for CVT-301 versus placebo were $-0.17 \mathrm{~L}$ versus $-0.16 \mathrm{~L}$, respectively.

\section{Safety and tolerability}

In both studies, there were no deaths and the most common CVT-301 TEAE was cough. The cough was generally transient and concurrent with capsule inhalation. In study A, none of the patients with cough had any other respiratory symptoms reported as TEAEs, nor experienced any changes in respiratory rate or spirometry: all resolved promptly and without treatment or intervention. ${ }^{(17)}$

Table 2. Study A: Spirometry Data for Predose Patients in ON and OFF States $(N=24)$

\begin{tabular}{|c|c|c|}
\hline \multirow[b]{2}{*}{ Parameter, mean (SD) [range] } & \multicolumn{2}{|c|}{ Motor state } \\
\hline & $O N(\mathrm{n}=191)$ & $O F F(\mathrm{n}=42)$ \\
\hline $\mathrm{FEV}_{1}, \mathrm{~L}$ & $3.114(0.874)[1.50-5.61]$ & $2.970(0.982)[1.38-5.27]$ \\
\hline FVC, L & $3.920(1.158)[1.83-10.10]$ & 3.849 (1.127) [2.06-6.62] \\
\hline $\mathrm{FEV}_{1} / \mathrm{FVC}, \%$ & $80.12(7.83)[31.0-97.0]$ & $76.92(9.35)[34.0-90.8]$ \\
\hline
\end{tabular}

$n$ refers to number of measurements.

$\mathrm{FEV}_{1}$, forced expiratory volume in 1 second; FVC, forced vital capacity. 


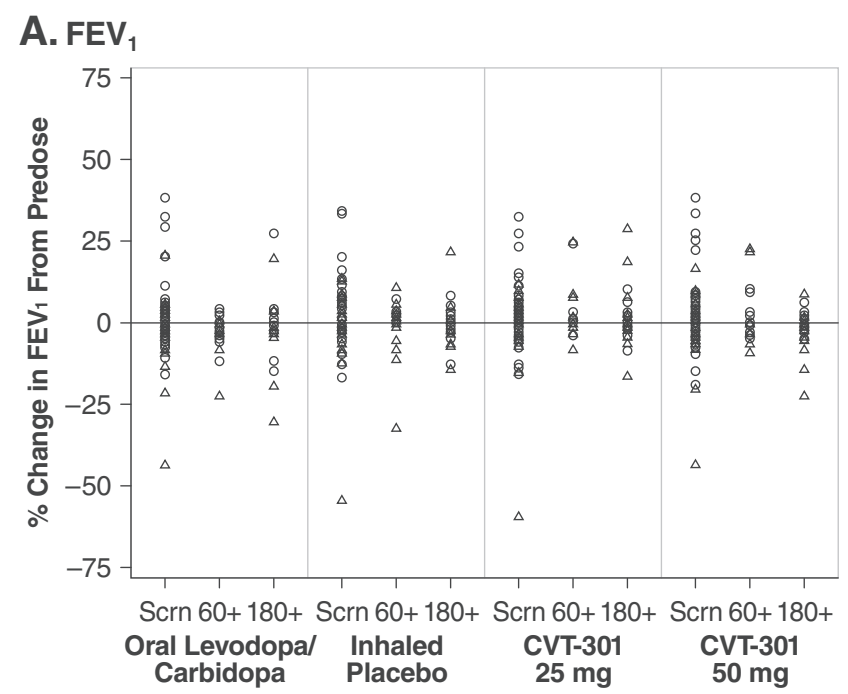

B. FEV $/$ FVC

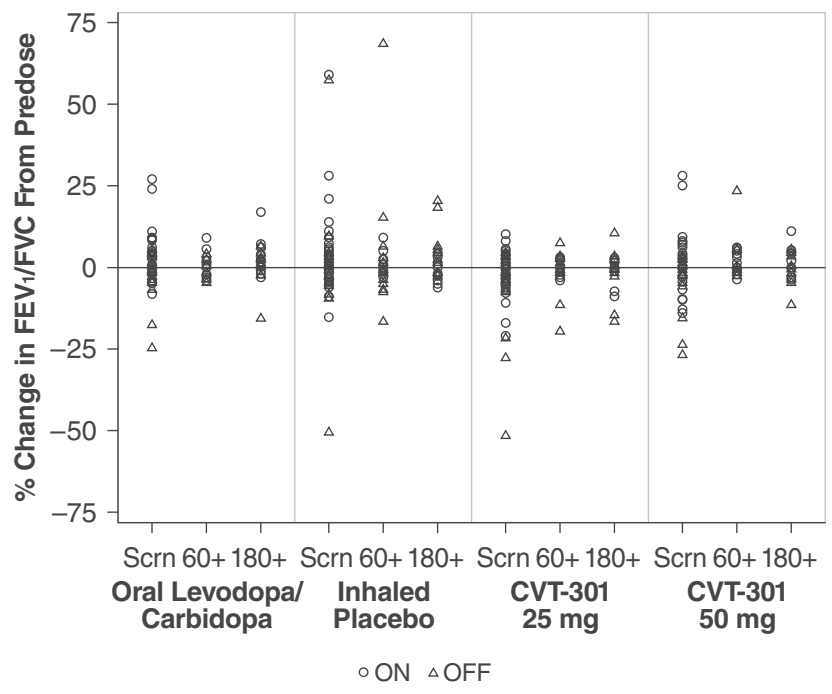

FIG. 2. Study A: Changes in lung function parameters for active control, placebo, and CVT-301 patients from predose to 180 minutes postdose. Each point represents an individual patient in an ON or OFF state. One patient was excluded from the analysis because of poor spirometry in the OFF state at screening, resulting in an inaccurate $\mathrm{FEV}_{1}$. $\mathrm{FEV}_{1}$, forced expiratory volume in 1 second; FVC, forced vital capacity; Scrn, screening.
Safety and incidence of TEAEs of study B have been reported previously by LeWitt et al. ${ }^{(13)}$ The most commonly reported TEAEs for CVT-301 were dizziness, cough, and nausea (in 3 patients [7\%] each). There were five cough events in total; one event for the placebo group and four for the CVT-301 groups. All AEs of cough were mild, unrelated to dose, and none led to withdrawal or dose modification. There were no AEs of dyspnea, wheezing, or bronchospasm. Dyskinesia was reported as a TEAE in one patient in the placebo group and one patient in the 50-mg CVT-301 group. No patients in either treatment group withdrew due to dyskinesia. Although one patient in the placebo group had dose reduction because of dyskinesia, there was no reporting of dyskinesia-related dose reduction in the CVT-301 group.

\section{Discussion}

Previously, we reported that CVT-301 provided improvement in OFF symptoms, with UPDRS Part III scores showing a treatment effect compared with placebo as early as 10 minutes, the first assessment time point. ${ }^{(13,17)}$ In this report, we discuss the pulmonary function as part of a safety evaluation of patients treated with CVT-301 or placebo.

Study A, which used spirometry to assess acute pulmonary function from predose to 3 hours postdose with CVT301 or placebo, showed that lung function did not differ between motor states, nor between CVT-301 and placebo groups. In addition, the number of patients who experienced a $10 \%$ reduction in $\mathrm{FEV}_{1}$ or $\mathrm{FVC}$ at any time point postdose was similar between all treatment groups.

It is interesting to note that there were some patients who experienced changes in $\mathrm{FEV}_{1}>20 \%$ or more, and that this was irrespective of their treatment. The observed fluctuations in $\mathrm{FEV}_{1}$ appeared to be effort-related, which may be due to the disease itself, as PD exacerbates age-related loss of respiratory muscle strength and rigidity and bradykinesia of thoracic musculature. ${ }^{(16,22,23)}$ A precise link between PD and respiratory dysfunction, however, has not been described. This issue may also represent a limitation for the interpretation of the present study.

In an earlier report, Hampson et al., ${ }^{(21)}$ using spirometry data from study B, evaluated the pulmonary function of all the patients during the screening process and longitudinally for those patients taking placebo. They noted that the mean spirometry results at screening were within normal ranges

Table 3. Study B: Longitudinal Spirometry Data from Baseline to Week 4 for CVT-301 and Placebo

\begin{tabular}{|c|c|c|c|c|c|c|}
\hline & & $F E V_{l}(L)$ & $\begin{array}{c}F E V_{1} \\
\text { (\% predicted) }\end{array}$ & $F V C(L)$ & $\begin{array}{c}F V C \\
(\% \text { predicted })\end{array}$ & $F E V_{l} / F V C(\%)$ \\
\hline Placebo & $\begin{array}{l}\text { Baseline mean } \pm \mathrm{SD} \\
\text { [range] }(n=43) \\
\text { Estimated change } \\
\text { from baseline to } \\
\text { week } 4[95 \% \mathrm{CI}]\end{array}$ & $\begin{array}{l}2.86 \pm 0.66 \\
{[1.31 \text { to } 4.11]} \\
-0.05 \\
{[-0.16 \text { to } 0.07]}\end{array}$ & $\begin{array}{l}89.2 \pm 17.4 \\
{[59.6 \text { to } 155.2]} \\
-2.1 \\
{[-5.7 \text { to } 1.5]}\end{array}$ & $\begin{array}{l}3.63 \pm 0.84 \\
{[1.68 \text { to } 5.18]} \\
-0.07 \\
\quad[-0.20 \text { to } 0.06]\end{array}$ & $\begin{array}{l}85.4 \pm 15.5 \\
{[57.3 \text { to } 137.0]} \\
-2.2 \\
{[-5.4 \text { to } 1.1]}\end{array}$ & $\begin{array}{l}79.1 \pm 5.9 \\
{[55.0 \text { to } 89.0]} \\
-0.6 \\
{[-1.7 \text { to } 0.5]}\end{array}$ \\
\hline CVT-301 & $\begin{array}{l}\text { Baseline mean } \pm \text { SD } \\
\text { [range] }(n=43) \\
\text { Estimated change } \\
\text { from baseline to } \\
\text { week } 4[95 \% \mathrm{CI}]\end{array}$ & $\begin{array}{l}2.64 \pm 0.60 \\
{[1.59 \text { to } 3.79]} \\
-0.06 \\
{[-0.17 \text { to } 0.05]}\end{array}$ & $\begin{array}{l}88.7 \pm 10.9 \\
{[63.1 \text { to } 112.5]} \\
-1.3 \\
{[-4.8 \text { to } 2.3]}\end{array}$ & $\begin{array}{l}3.35 \pm 0.74 \\
{[2.06 \text { to } 4.79]} \\
-0.07 \\
{[-0.19 \text { to } 0.06]}\end{array}$ & $\begin{array}{l}85.7 \pm 10.3 \\
{[63.2 \text { to } 116.5]} \\
-0.9 \\
{[-4.0 \text { to } 2.3]}\end{array}$ & $\begin{array}{l}78.8 \pm 4.2 \\
{[66.0 \text { to } 89.0]} \\
-1.1 \\
{[-2.1 \text { to } 0.0]}\end{array}$ \\
\hline $\begin{array}{l}\text { CVT-301 } \\
\text { vs. Placebo }\end{array}$ & $\begin{array}{l}\text { Estimated difference } \\
\text { at week } 4 \\
{[95 \% \mathrm{CI}]}\end{array}$ & $\begin{array}{l}-0.01 \\
{[-0.15 \text { to } 0.12]}\end{array}$ & $\begin{array}{l}0.9 \\
{[-3.3 \text { to } 5.0]}\end{array}$ & $\begin{array}{l}0.00 \\
{[-0.15 \text { to } 0.16]}\end{array}$ & ${ }_{[-2.6}^{1.3}$ to 5.1$]$ & $\stackrel{-0.5}{[-1.6 \text { to } 0.7]}$ \\
\hline
\end{tabular}

$\mathrm{CI}$, confidence interval; $\mathrm{FEV}_{1}$, forced expiratory volume in 1 second; $\mathrm{FVC}$, forced vital capacity; SD, standard deviation. 
and were not dependent on motor state (ON vs. OFF). Based on the findings, the authors concluded that it is feasible to obtain longitudinal spirometry measurements of acceptable quality (ATS criteria) in PD patients with motor fluctuation.

In this report, using all the patients in study B, we show that longitudinal spirometry data obtained from a majority (77\%) of patients were of acceptable ATS-quality, regardless of treatment or motor state. Consistent with the acute spirometry findings from study $\mathrm{A}$, there were no significant differences in $\mathrm{FEV}_{1}, \mathrm{FVC}$, and $\mathrm{FEV}_{1} / \mathrm{FVC}$ ratios between those treated with CVT-301 versus inhaled placebo over 4 weeks of treatment as shown in Table 2. The $\mathrm{FEV}_{1} / \mathrm{FVC}$ ratio, a measure of potential airway obstruction, did not change appreciably from baseline, suggesting that CVT-301 treatment was not associated with any evidence of acute airflow obstruction.

Inhalation of the placebo or CVT-301 particles from the inhaler produced no significant changes in lung function parameters over the duration of the study, and there were no AEs such as dyspnea, wheezing, or bronchospasm. The TEAEs of cough were generally mild in study A (70\% were mild and $30 \%$ were moderate) and were experienced by $25 \%$ of patients. In study $\mathrm{B}$, however, despite having a considerably longer exposure to inhalation, the number of cough TEAEs was fewer, affecting only $7 \%$ of patients (five events in total).

In conclusion, in this population of patients treated with CVT-301 pulmonary parameters did not vary significantly between ON and OFF states at screening, or over the one month of treatment with drug or placebo. Common AEs with CVT-301 were cough, dizziness, and nausea. Treatment with CVT-301 did not increase the incidence of dyskinesia as a reported TEAE.

\section{Acknowledgments}

This study was supported by Civitas Therapeutics, Inc., now wholly owned by Acorda Therapeutics, Inc. Editorial assistance was provided by Robin Smith, PhD, of The Curry Rockefeller Group, LLC, and this assistance was funded by Acorda Therapeutics, Inc.

\section{Author Disclosure Statement}

P.A.L. has received compensation for advisory services, consulting, research grant support, or speaker honoraria from AbbVie, Acadia, Acorda Therapeutics, Inc., Adamas, Biogen Idec, Biotie, Cynapsus, Depomed, Impax, Insightec, Intec, International Parkinson's Disease and Movement Disorders Society, Ipsen, Kyowa, Lundbeck, Luye, Michael J. Fox Foundation for Parkinson's Research, NeuroDerm, Noven, Parkinson Study Group, Pfizer, Pharma 2B, ProStrakan, SynAgile, Teva, Tremor Research Group, UCB, U.S. WorldMeds, World Parkinson Congress, and XenoPort.

R.P. has received compensation for advisory services, consulting, research grant support, or speaker honoraria from AbbVie, Acadia, Acorda Therapeutics, Inc., Acorda/Civitas, Adamas, Avid, Biotie, Boston Scientific, Cynapsus, Kyowa, Lundbeck, Medtronic, Neurocrine, NIH/NINDS, NPF, Parkinson Study Group, Pfizer, Sage, St Jude Medical, Teva Neuroscience, UCB, and U.S. WorldMeds.

A.S., A.C., and R.B. are employees and stockholders of Acorda Therapeutics, Inc. H.M. was an employee of Acorda
Therapeutics, Inc. at the time of study and during the development of this article.

\section{References}

1. LeWitt PA: Levodopa therapy for Parkinson's disease: Pharmacokinetics and pharmacodynamics. Mov Disord. 2015;30:64-72.

2. Baruzzi A, Contin M, Riva R, Procaccianti G, Albani F, Tonello C, Zoni E, and Martinelli P: Influence of meal ingestion time on pharmacokinetics of orally administered levodopa in parkinsonian patients. Clin Neuropharmacol. 1987;10:527-537.

3. Fasano A, Visanji NP, Liu LW, Lang AE, and Pfeiffer RF: Gastrointestinal dysfunction in Parkinson's disease. Lancet Neurol. 2015;14:625-639.

4. Goetze O, Nikodem AB, Wiezcorek J, Banasch M, Przuntek $\mathrm{H}$, Mueller T, Schmidt WE, and Woitalla D: Predictors of gastric emptying in Parkinson's disease. Neurogastroenterol Motil. 2006;18:369-375.

5. Robertson DR, Renwick AG, Wood ND, Cross N, Macklin BS, Fleming JS, Waller DG, and George CF: The influence of levodopa on gastric emptying in man. Br J Clin Pharmacol. 1990;29:47-53.

6. Deleu D, Northway MG, and Hanssens Y: Clinical pharmacokinetic and pharmacodynamic properties of drugs used in the treatment of Parkinson's disease. Clin Pharmacokinet. 2002;41:261-309.

7. Olanow CW, Stern MB, and Sethi K: The scientific and clinical basis for the treatment of Parkinson disease (2009). Neurology. 2009;72:S1-S136.

8. Jenner P: Treatment of the later stages of Parkinson's diseasepharmacological approaches now and in the future. Transl Neurodegener. 2015;4:3.

9. Frijlink HW, and De Boer AH: Dry powder inhalers for pulmonary drug delivery. Expert Opin Drug Deliv. 2004;1: 67-86.

10. Luinstra M, Rutgers AW, Dijkstra H, Grasmeijer F, Hagedoorn P, Vogelzang JM, Frijlink HW, and de Boer AH: Can patients with Parkinson's disease use dry powder inhalers during off periods? PLoS One. 2015;10:e0132714.

11. Sakagami M: In vivo, in vitro and ex vivo models to assess pulmonary absorption and disposition of inhaled therapeutics for systemic delivery. Adv Drug Deliv Rev. 2006; 58:1030-1060.

12. Freed M, Grosset D, and Worth PF, et al.: Rapid levodopa augmentation following inhaled CVT-301 results in rapid improvement in motor response when administered to PD patients in the "off"' state [abstract]. Neurology. 2014;82: S7.007.

13. LeWitt PA, Hauser RA, Grosset DG, Stocchi F, Saint-Hilaire MH, Ellenbogen A, Leinonen M, Hampson NB, DeFeoFraulini T, Freed MI, and Kieburtz KD: A randomized trial of inhaled levodopa (CVT-301) for motor fluctuations in Parkinson's disease. Mov Disord. 2016;31:1356-1365.

14. Brown LK: Respiratory dysfunction in Parkinson's disease. Clin Chest Med. 1994;15:715-727.

15. Shill H, and Stacy M: Respiratory function in Parkinson's disease. Clin Neurosci. 1998;5:131-135.

16. Sabate M, Rodriguez M, Mendez E, Enriquez E, and Gonzalez I: Obstructive and restrictive pulmonary dysfunction increases disability in Parkinson disease. Arch Phys Med Rehabil. 1996;77:29-34.

17. Lipp MM, Batycky R, Moore J, Leinonen M, and Freed MI: Preclinical and clinical assessment of inhaled levodopa for 
OFF episodes in Parkinson's disease. Sci Transl Med. 2016;8:360ra136.

18. Hankinson JL, Odencrantz JR, and Fedan KB: Spirometric reference values from a sample of the general U.S. population. Am J Respir Crit Care Med. 1999;159:179-187.

19. DeLong M, Wright J, Dawson M, Meyer T, Sommerer K, and Dunbar C: Dose delivery characteristics of the AIR pulmonary delivery system over a range of inspiratory flow rates. J Aerosol Med. 2005;18:452-459.

20. Miller MR, Hankinson J, Brusasco V, Burgos F, Casaburi R, Coates A, Crapo R, Enright P, van der Grinten CP, Gustafsson P, Jensen R, Johnson DC, MacIntyre N, McKay R, Navajas D, Pedersen OF, Pellegrino R, Viegi G, and Wanger J: Standardisation of spirometry. Eur Respir J. 2005;26:319-338.

21. Hampson NB, Kieburtz KD, LeWitt PA, Leinonen M, and Freed MI: Prospective evaluation of pulmonary function in Parkinson's disease patients with motor fluctuations. Int $\mathbf{J}$ Neurosci. 2017; 127:276-284.

22. Guedes LU, Rodrigues JM, Fernandes AA, Cardoso FE, and Parreira VF: Respiratory changes in Parkinson's dis- ease may be unrelated to dopaminergic dysfunction. Arq Neuropsiquiatr. 2012;70:847-851.

23. Sabate M, Gonzalez I, Ruperez F, and Rodriguez M: Obstructive and restrictive pulmonary dysfunctions in Parkinson's disease. J Neurol Sci. 1996;138:114-119.

Received on November 2, 2016 in final form, August 17, 2017

Reviewed by: David Cipolla

Susan Fox

Address correspondence to:

Peter A. LeWitt, MD

Department of Neurology

Henry Ford Hospital-West Bloomfield 6777 West Maple Road

West Bloomfield, MI 48322

E-mail: plewitt1@hfhs.org 